\title{
An IDEA Model Analysis of Instructional Risk Communication in the Time of Ebola
}

\author{
Deborah D. Sellnow-Richmond $\mathbb{0},{ }^{\text {a }}$ Amiso M. George, ${ }^{b}$ \\ and Deanna D. Sellnow (10 ${ }^{c}$
}

\author{
aDepartment of Communication, Columbus State University; bStrategic \\ Communication Department, Texas Christian University; 'Nicholson School \\ of Communication, University of Central Florida
}

\begin{abstract}
The Ebola outbreak and its rapid spread throughout West Africa and other countries was a megacrisis that imposed numerous challenges to those communicating to nonscientific publics about the epidemic. This article examines the instructional risk messages offered in the days that followed the 2014 infection and death of Liberian national Thomas Eric Duncan in Dallas, Texas. More specifically, we apply the IDEA model for effective instructional risk and crisis communication embellished by exemplification theory to conduct a thematic analysis of messages offered locally (Dallas news stories and press releases), nationally (Centers for Disease Control and Prevention Live Chat Twitter posts), and internationally (website content from the World Health Organization, the United Nations Children's Fund, and Doctors Without Borders). Our conclusions reveal that the majority of messages offered from each organization privileged the element of explanation over internalization and action as well as negative over positive exemplification. On the basis of these conclusions, and informed by previous research, we propose a number of potential implications and recommendations for offering a balanced representation among internalization, explanation, and action as proposed in the IDEA model. We also suggest that positive exemplification could be used strategically to motivate receivers to attend to these messages (internalization), reduce potential misunderstandings (explanation), and take appropriate self-protective actions (action). Agency spokespersons and media reporters may find the conclusions and recommendations drawn from this analysis to be useful when crafting similar instructional risk preparedness and crisis response messages.
\end{abstract}

KEYWORDS: IDEA model; exemplification theory; Ebola; megacrisis; instructional risk and crisis communication

Instructing nonscientific publics to take appropriate self-protective actions during risk and crisis events is an ongoing challenge for crisis communicators (e.g., Coombs, 2009; Rowan, Botan, Kreps, Samoilenko, \& Farnsworth, 2009). This is due, in part, to the imminent threat

CONTACT Deborah D. Sellnow-Richmond,PhD•E-mail: sellnowrichmond_deborah@columbusstate.edu - 203 Carpenter's Building, \#4 9th St., Columbus, GA 31904 
imposed, the potential consequences of wrong actions or inaction, the need to translate scientific information accurately and intelligibly to disparate nonscientific publics, and the short response time afforded for delivering such instructions (e.g., Seeger, 2006; D. D. Sellnow \& Sellnow, 2014b; T. L. Sellnow \& Seeger, 2013). More specifically, some of the major challenges communicators face when instructing nonscientific publics during a risk or crisis event focus on (in)accessibility of some people and groups to receive the messages delivered via certain channels, lack of motivation among some people and groups to attend to them, misinformation in and misinterpretation of messages, distrust of the message source, and a lack of clarity about what actions to take for self-protection. Consequently, instructional risk and crisis communication is emerging as an insightful body of research for measuring the affective, cognitive, and behavioral learning outcome effectiveness of such messages (e.g., Frisby, Sellnow, Lane, Veil, \& Sellnow, 2013; Frisby, Veil, \& Sellnow, 2014; D. D. Sellnow, Lane, Sellnow, \& Littlefield, 2017; D. D. Sellnow, Limperos et al., 2015; D. D. Sellnow \& Sellnow, in press). The rise of megacrises in recent years has increased both the sense of urgency felt during risk and crisis events and the complexity of communicating instructions successfully during them (Helsloot, Boin, Jacobs, \& Comfort, 2012). Megacrises "defy boundaries, limits, neat demarcations, patterned connections and linear consequences" (p. 5). Moreover, because megacrises do not respect preconceived boundaries or national borders, they often have an extensive global impact. Consequently, timely and effective responses are even more critical, as well as more difficult to achieve. Some of the most compelling examples include health epidemics and pandemics such as AIDS, BSE, SARS, and $\mathrm{H}_{1} \mathrm{~N}_{1}$. A case of the Ebola virus disease appeared in a small village in Guinea in December 2013 but was not identified as Ebola until March 2014. In the months that followed, the world would experience a megacrisis epidemic as the disease spread quickly throughout the region and to several other countries (World Health Organization, 2015). Although travel warnings and bans were put into place in an attempt to contain the spread of the virus, the gestation period can range from several weeks to months (Centers for Disease Control and Prevention, 2015). Thus travelers could (and did) easily spread the disease unknowingly. 
Containing the transmission of Ebola and communicating accurate and effective instructional messages for self-protection became serious challenges.

When Liberian native Thomas Eric Duncan traveled from Liberia to Dallas, Texas, in September 2014 and then died from the Ebola disease one month later, the megacrisis became a real perceived threat in the minds of the American people. Hysteria ruled as nonscientific publics wrestled with uncertainty about the disease. News media offered wall-to-wall coverage of the virus, politicians and pundits weighed in urging travel bans of all persons arriving from Africa (not just the affected regions), parents withdrew their children from schools, and people living in the same apartment complex as Duncan were scared for their own health and safety.

The apartment of the first nurse to contract Ebola from Duncan, Nina Pham, was quarantined. Neighbors were alarmed, and some even moved away. Another nurse who treated Duncan, Amber Vinson, studied nursing at Kent State University (KSU) in Ohio. When Vinson contracted Ebola, officials at KSU banned both her mother and two other family members who worked at the university from campus for 21 days because of their contact with Ms. Vinson. The airline that Ms. Vinson flew on to and from Ohio forced employees who had been in contact with her to take paid leave. Other passengers were worried about potentially contracting the disease from Ms. Vinson, although she had received permission from the Centers for Disease Control and Prevention (CDC) to travel prior to doing so.

Communication experts agree that much of the hysteria was exacerbated by the conflicting and contradictory messages the public got from the media, Texas Health Presbyterian Hospital officials, and the CDC. This article examines instructional risk messages communicated to nonscientific publics during the 2014 Ebola crisis as a means to improve such messages when megacrisis epidemics arise in the future. We begin by describing the Duncan case, as it illustrates how the Ebola epidemic moved from a crisis event in West Africa to a megacrisis crossing national borders. We then clarify the IDEA model for effective instructional risk and crisis message design grounded in experiential learning theory and embellished with exemplification theory as well 
as the methods we employed to answer our research questions. Next, we describe the results of our analysis of (a) messages sent via a CDC live chat on Twitter, (b) news stories and press releases distributed in the Dallas-Fort Worth area, and (c) messages offered on the websites of the World Health Organization (WHO), the United Nations Children's Fund (UNICEF), and Doctors Without Borders (Médecins Sans Frontières; MSF) during the peak of the crisis in the United States. Finally, we offer a discussion as to how this analysis can inform future decisions about effective instructional risk and crisis messages during megacrisis events, as well as propose suggestions for future research.

\section{The Case}

When Liberian national Thomas Eric Duncan sought medical care at Texas Health Presbyterian Hospital in Dallas on September 25, 2014, for a sharp headache, fever, and other symptoms, no one predicted that he would be the first Ebola victim identified in Texas. Duncan allegedly traveled knowingly to the United States after having contracted Ebola in Liberia. A few weeks earlier, Kent Brantly and Nancy Writebol, both medical missionaries who contracted Ebola while working in Liberia, were airlifted to Emory University Hospital in Atlanta, treated with the experimental drug ZMapp, and made full recoveries. Duncan, however, was sent home from the Dallas hospital with antibiotics. Three days later, on September 28, Duncan was rushed to the hospital in an ambulance and placed in isolation.

During this time, Duncan's apartment was not decontaminated, and family members in the apartment were not quarantined nor told to take any precautionary actions. News media broadcast speculations about the prospect of others contracting the disease. The Richardson Independent School District near Dallas pulled from school three children who had reportedly had contact with Duncan. Many parents worried about the safety of their own children and withdrew them from the Richardson schools as well. Meanwhile, Duncan's health deteriorated. He died on October 8, 2014.

Two days after Duncan's death, Nina Pham, a 26-year-old nurse who had treated Duncan at Texas Health Presbyterian Hospital, reported 
fever symptoms. She was immediately placed in isolation at the same hospital. Her dog was seized and quarantined. Her frightened neighbors told television reporters that they had no information about what precautions to take. Fortunately, Pham was discharged as healthy on October 24, as documented in photos taken of President Obama hugging her in the Oval Office.

Despite complaining of a fever, another nurse who had treated Duncan, 29-year-old Amber Vinson, was cleared by the CDC to fly from Dallas to Ohio to visit family. After returning to Dallas, Vinson began experiencing Ebola symptoms, was admitted to the hospital, and was placed in isolation. However, some parents believed Vinson may have been in contact with some schoolchildren before she was admitted to the hospital and pressed the schools to shut down. Passengers who flew on the same plane as Vinson to and from Ohio were equally concerned. The inconsistent and contradictory messages coming from the CDC and the Texas Health Presbyterian Hospital, the frightening images of hazmat-clad health and emergency workers that played out in the media, and the politicians and pundits declaring gloom and doom heightened public fears about the virus.

Although the hospital, the city of Dallas, the Dallas news media, and the CDC eventually improved their messaging, the mismanagement of key risk communication during these crucial first few hours and days of the breaking crisis caused considerable anxiety and confusion among members of the public. Thus this project focuses on improving instructional risk and crisis communication messages offered in times of urgent threat (real or perceived) to individuals and groups using this Ebola event as a case study. More specifically, we conducted a thematic analysis of messages disseminated to the public according to the IDEA model of effective instructional risk and crisis communication embellished by exemplification theory as they may influence affective learning (perceived value/utility/relevance), cognitive learning (comprehension/ understanding), and behavioral learning (self-efficacy/behavioral actions). The following section provides a rationale for grounding our analysis theoretically in the IDEA model and exemplification theory. 


\section{Theoretical Grounding}

This study is grounded in the IDEA model for effective instructional risk and crisis messages (D. D. Sellnow \& Sellnow, 2014b) and extended with exemplification theory (Zillmann, 1999). The IDEA model is grounded in experiential learning theory as first conceived by John Dewey (1938) and then extended by David Kolb (1984) and colleagues.

The components of the IDEA model are internalization (perceived value and relevance via proximity, personal impact, and timeliness), distribution (multiple channels-such as TV, radio, social media, smartphones-through which such messages are/should be delivered), explanation (accurate science from credible sources translated intelligibly to nonscientific publics), and action (specific steps to take/not to take for self-protection in a given risk or crisis situation; D. D. Sellnow \& Sellnow, 2014b). In the case of a health crisis event, effective instructional risk messages would include mention of the potential effects of the disease on people who become infected, how much time one has to notice symptoms and to seek medical help, and where the disease is appearing (internalization). Such messages would also explain what the disease is and how it is contracted in simple, nonscientific language (explanation). Finally, such messages would propose specific actions to take (or not to take) to avoid contracting the disease as well as what to do (or not to do) if one has been exposed to an infected individual or is experiencing any of the symptoms (action). This consistent message ought to be delivered by a variety of credible sources via multiple channels (distribution) to ensure as many people as possible receive it and to reduce the number of inaccurate, misleading, or conflicting messages.

We selected the IDEA model because it has demonstrated its utility across risk and crisis types, among disparate cultural groups, and across international borders (e.g., Frisby et al., 2014; Littlefield et al., 2014; D. D. Sellnow, Iverson, \& Sellnow, 2017; D. D. Sellnow, Johansson, Sellnow, and Vigso, 2016; D. D. Sellnow, Limperos et al., 2015; T. L. Sellnow, Sellnow, Lane, \& Littlefield, 2012). In essence, the IDEA model provides a framework for designing effective messages when the goal is to instruct nonscientific publics to take appropriate actions for selfprotection during risk and crisis events. 
Exemplification theory (Zillmann, 1999) is also used in this analysis as it enhances several elements of the IDEA model. Exemplification theory centers on the notion that everyone is familiar with examples and how examples can represent large and complex ideas in comprehensible ways. The key to exemplification is the "recognition of shared features between an example (aka exemplar) and the exemplified, as well as between all possible examples of the exemplified" (p. 72). Exemplars are essentially evocative words, phrases, images, and sometimes sounds that serve as cognitive shortcuts to glean meaning about complex ideas or situations (Eagly \& Chaiken, 1993; Zillmann, 2002, 2006). In other words, they are easy to understand and process with limited (if any) analytic thought. Exemplification operates in three distinct ways.

First, exemplification theory argues that information is evaluated subjectively, relying on biases in making risk assessments rather than assessing risk systematically (Zillmann \& Brosius, 200o). It also supposes that risk perception is altered through exposure to exemplars. Exemplars are made memorable through the use of "visually vivid and emotionally strong" (Aust \& Zillmann, 1996, p. 788) words and images. Exemplars can come in the form of "any combination of image and text" (Zillmann, 2006, p. S224) that influences risk perception when viewed frequently and recently.

Second, an exemplar represents a group of similar cases through one instance (e.g., one individual who suffers the effects of fetal alcohol spectrum disorder represents all fetuses that have the potential to be born with similar disadvantages if the mother chooses to drink alcohol while pregnant). Zillmann (2006) argued that exemplification theory functions by means of a "quantification heuristic," suggesting that frequency of exemplars are continually monitored and the prevalence of a particular exemplar directly impacts its retrieval from one's memory.

Third, exemplars can have a positive (e.g., "superfood" as healthy foods) or negative (e.g., "Frankenfood" as unhealthy foods) valence. In the case of the Ebola megacrisis, we argue that negative exemplification fueled misperceptions and triggered fear among a variety of publics about its symptoms, how it is spread, how to protect oneself from contracting it, and how to treat it.

Exemplification theory in combination with the IDEA model is 
particularly suitable for examining the instructional risk messages sent during the fall 2014 Ebola outbreak that occurred in the United States. By understanding how exemplars were used in the context of the IDEA model, the ways in which exemplars may affect individuals' understanding of a crisis event like Ebola as well as their decisions to follow recommended self-protective actions may become apparent. To clarify, the use of exemplars may help people internalize the relevance and potential impact of Ebola on them and their loved ones. Similarly, exemplars might serve as effective cognitive shortcuts to increase understanding of complex information about the virus (explanation) and, ultimately, to foster appropriate self-protective actions (Spence, Lachlan, Lin, Sellnow-Richmond, \& Sellnow, 2015).

On the basis of the implications of the messages sent during the Ebola megacrisis in the United States and the tenets of the IDEA model and exemplification theory, the authors sought to answer the following four research questions (RQs):

RQ1: In what ways do Ebola crisis messages distributed by the CDC during a live chat on Twitter employ elements of the IDEA model for effective instructional risk and crisis communication?

RQ1a: In what ways do Ebola crisis messages distributed by the CDC during a live chat on Twitter employ elements of internalization? RQ1b: In what ways do Ebola crisis messages distributed by the CDC during a live chat on Twitter employ elements of explanation? RQ1c: In what ways do Ebola crisis messages distributed by the CDC during a live chat on Twitter employ elements of action?

RQ1d: In what ways is exemplification used in communicating internalization, explanation, and action during the CDC Ebola live chat on Twitter?

RQ2: In what ways do Ebola crisis messages distributed via Dallas area news stories and press releases employ elements of the IDEA model for effective instructional risk and crisis communication?

RQ2a: In what ways do Ebola crisis messages distributed via Dallas area news stories and press releases employ elements of internalization?

RQ2b: In what ways do Ebola crisis messages distributed via Dallas 
area news stories and press releases employ elements of explanation?

RQ2c: In what ways do Ebola crisis messages distributed via Dallas area news stories and press releases employ elements of action? RQ2d: In what ways is exemplification used in communicating internalization, explanation, and action in the Dallas area Ebola news stories and press releases?

RQ3: In what ways do Ebola crisis messages distributed via websites sponsored by the WHO, UNICEF, and MSF employ elements of the IDEA model for effective instructional risk and crisis communication? RQ3a: In what ways do Ebola crisis messages distributed via websites sponsored by the WHO, UNICEF, and MSF employ elements of internalization?

RQ3b: In what ways do Ebola crisis messages distributed via websites sponsored by the WHO, UNICEF, and MSF employ elements of explanation?

RQ3c: In what ways do Ebola crisis messages distributed via websites sponsored by the WHO, UNICEF, and MSF employ elements of action?

RQ3d: In what ways is exemplification used in communicating internalization, explanation, and action about Ebola on the websites sponsored by the WHO, UNICEF, and MSF?

RQ4: What similarities and differences exist regarding IDEA model components embellished by exemplification in Ebola crisis messages distributed via the CDC live Twitter chat, Dallas news stories and press releases, and websites sponsored by the WHO, UNICEF, and MSF?

\section{Method}

The research team conducted a thematic analysis of all messages sent by several key entities during the first hours, days, and weeks of the 2014 Ebola outbreak in the United States. More specifically, all messages sent during a CDC-hosted live question-and-answer Twitter chat on October 2, 2014; all Dallas news stories and press releases published between September 24 and October 31, 2014; and all website content published by the WHO, UNICEF, and MSF during that same period were examined. 
Before conducting the analysis, the researchers consulted with Ebola experts at the CDC to collect accurate information about the infection, how it is spread, its symptoms, and the actions people should take for self-protection. To ascertain the kinds of information being shared with general publics, the researchers also collected information from the Texas Health Presbyterian Hospital in Dallas, official documents from the city of Dallas, Dallas newspapers and TV reports, and news releases from universities and schools in the Dallas-Fort Worth area. Doing so ensured ecological validity, accurate scientific information, and a comprehensive understanding of what messages were being conveyed at the time.

\section{Sample}

Because research has suggested that different publics perceive different entities as more and less credible (T. L. Sellnow \& Seeger, 2013), the research team examined messages from multiple sources: the CDC, Dallas area news media and health agencies, and three international health organizations (WHO, UNICEF, and MSF). Also, on the basis of previous research suggesting that different publics seek information via a variety of media channels (Anthony \& Sellnow, 2011, 2016), messages distributed via a variety of channels (Twitter, traditional news media and press releases, and organization websites) were examined. Finally, the research team focused on messages that may be accessed easily online (as well as via other outlets) because the Internet is becoming an increasingly popular source for both relaying news and seeking information (Rosenstiel, Mitchell, Purcell, \& Rainie, 2011).

The authors collected all of the tweets exchanged during the CDC question-and-answer Twitter session held on October 2, 2014. To clarify, the CDC hosted a live chat for individuals concerned about contracting the Ebola virus after Duncan was reported to have tested positive. The authors also collected all Dallas area news stories and press releases discussing the virus and this incident from September 24 to October 31, 2014. Finally, all Ebola-related material posted on three international organizations' websites (WHO, UNICEF, and MSF) was collected and used to contextualize the messages about the Ebola virus from the perspective of the global community. In all, this comprehensive census 
of data collected from September 24, 2014, through October 31, 2014, yielded 282 tweets, 31 local news stories, and 38 international organization website articles.

\section{Procedure}

An etic approach was used to analyze the content of messages distributed from these disparate sources via these diverse channels (Lindlof \& Taylor, 2011). To clarify, an etic approach uses established "conceptual categories provided by our disciplinary knowledge and theory" (p. 95). In this case, message content was coded according to the internalization, explanation, and action components described in the IDEA model as well as for the use of positive or negative exemplars within each component. Two researchers developed a codebook, which was then used to examine all message content (see the appendix). Any disagreements were resolved through discussion. The messages were examined for the presence (or lack thereof) of each element as well as the role of exemplification in them. From these results, conclusions and implications were drawn regarding instructional risk messages conveyed in this case as well as for informing similar message content and design in future crisis and megacrisis events.

\section{Results}

\section{Research Question 1}

To evaluate the use of the IDEA model elements in the CDC's Twitter live chat, 282 tweets were thematically coded for internalization, explanation, and action as well as the incorporation of exemplification within each of these elements. ${ }^{1}$ Of these 282 tweets, 61 (21\%) incorporated elements of internalization. For example, Jacin tweeted, "Press conference said asymptomatic people aren't contagious; Travel guidance on CDC site suggests otherwise. What gives?" The CDC responded, "People aren't contagious during incubation period; they're only contagious when they start having symptoms." Jacin's fears appeared to be averted: "Then there is no need for United Airlines to be contacting all of those passengers? Simply over-abundance of precaution?" And the CDC confirmed, "Since the patient didn't develop 
symptoms until AFTER travel, there was no risk to other passengers."

Of these 282 tweets, 250 (88\%) focused on elements explanation. For example, in response to Rawlings's question about how patients are being treated, the $\mathrm{CDC}$ responded, "Patients are given supportive care. Some experimental treatments are being tried." And in response to Apodaca's query about Ebola surviving on sterile surfaces for 6 days, the CDC responded that it cannot do so unless it is in body fluid, does not survive long outside of the body, and is only contagious if a person is experiencing active symptoms. In numerous other exchanges, CDC experts not only responded but also pointed to websites where participants could get more information and explanation about the virus, how it is spread, and what is being done to contain it.

Of these 282 tweets, 53 (19\%) incorporated elements focused on action steps. For example, Em D tweeted, "Does ebola respond to 'Purell' and alcohol based sanitizer, or soap and water? How about bleach?" The CDC responded that "alcohol-based hand sanitizer and chlorine can kill Ebola." Sometimes, however, the action steps were not specific, as was the case when the CDC responded to Galiano's query about how to properly disinfect and what product to use by saying, "Use an EPA-approved hospital grade disinfectant." Finally, as was the case with internalization, many times the $\mathrm{CDC}$ experts responded to queries about self-protective actions by pointing participants to a website for more information. For example, when Victory Healthcare asked, "What symptoms should someone look out for, in regards to Ebola?" The CDC responded with, "Here are new resources: go.usa.gov/vEwP"

In terms of exemplification, only 9 (less than $1 \%$ ) of the 282 tweets used exemplars, and 8 of the 9 instances represented negative rather than positive exemplification. More specifically, only 3 (less than 1\%) of the 61 tweets that focused on internalization incorporated exemplars, and all 3 were negative. For example, Robrod4g wrote, "I have a 7 yr. old \& a 7 mo. pregnant wife who works in the health care community. YES! I AM SCARED!!" The CDC responded, "Understandable, \#Ebola is scary. New threat \& deadly disease." Six (less than $1 \%$ ) of the 250 tweets focused on explanation-incorporated exemplars. Only one of these was coded as a positive exemplar by using a graphic illustration as a cognitive shortcut regarding how the Ebola virus is contracted 


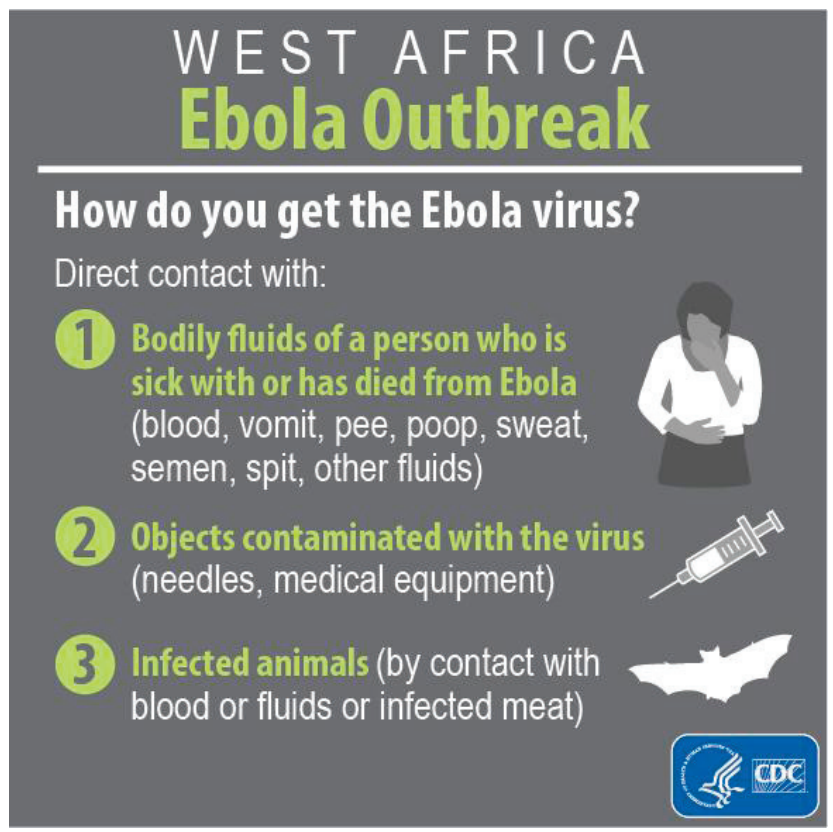

FIGURE 1 Positive explanation exemplar.

(see Figure 1). No exemplars were identified in the tweets that focused on action steps. Ultimately, a majority (88\%) of the live chat tweets emphasized explanations of the situation and events, and fewer than $1 \%$ offered exemplars.

\section{Research Question 2}

In total, 31 news stories and press releases focused on Ebola were published in the Dallas area between September 24 and October 31, 2014. These reports were collected and thematically coded for internalization, explanation, and action as well as the incorporation of exemplification in each of these elements. Of these 31 publications, 10 (32\%) incorporated internalization. For example, an initial statement published by the Dallas Independent School District (2014) began with a note of compassion by saying, "The health and safety of our students is always our top priority" and then addressed proximity and personal impact by revealing that the five students who may have had contact with the infected individual had "been advised to stay home from school." 
Similarly, a Texas Christian University (2014) press release reported that "TCU is aware of the confirmation of an Ebola case in Dallas, Texas (proximity). The University is in contact with local health care officials and will continue to monitor the situation and keep families, students, faculty, and staff informed during this time" (compassion, relevance, personal impact, timeliness).

Nearly every article - that is, 30 (97\%) of 31-incorporated elements of explanation. A common theme throughout them was a statement refuting a common misunderstanding that Ebola could be spread through the air. These refutations were then typically followed by a statement explaining that Ebola is only spread via "direct contact with the body fluids of a person showing symptoms of the illness" and that the risk of contracting it was very low according to both "national and local health officials" (source credibility; Southern Methodist University, 2014). Another common theme focused on the steps being taken by government agencies, health care providers, and other area experts to manage the outbreak. For example, the Governor's Press Office (2014) released a statement announcing "the creation of a state-of-the-art Ebola treatment and infectious disease bio containment facility in North Texas" that would "allow us to act quickly to limit the virus' reach and give patients the care they need."

Regarding the action element, only 2 (6\%) of the 31 articles proposed specific action steps. Instead, many of them simply pointed readers to seek such information from additional websites, such as the Tarrant County Health Department, the Texas Department of State Health Services, or the CDC. The reports that did offer specific action steps tended merely to discourage "travel to the affected African counties," to monitor people for symptoms, and to "see a physician in a medical setting for an evaluation" when symptoms emerged (Texas Wesleyan University, 2014).

Finally, 7 of the 31 articles (22\%) offered negative exemplars, and none used positive exemplars. More specifically, 2 (20\%) of the 10 articles that incorporated internalization did so with the use of exemplars. For example, one NBC Dallas-Fort Worth story described Ebola as "a fire straight from the pit of hell" (Young, 2014). Five (16\%) of the 30 articles that focused on explanation incorporated exemplars to aid explanation. 
For example, WFAA, an ABC Dallas news affiliate, reported that the "once-bustling" Texas Health Presbyterian hospital had turned into a "ghost town," accompanied by photographs of empty hallways and waiting rooms (Lupkin, 2014). No exemplars were offered as cognitive shortcuts for specific action steps. In sum, as was the case with the CDC Twitter exchange, nearly all of the Dallas area news stories and press releases emphasized explanation over internalization or action and offered only negative exemplification.

\section{Research Question 3}

To examine the use of IDEA model elements among international health organizations, all 38 Ebola-related articles posted on WHO, UNICEF, and MSF websites between September 24 and October 31, 2014, were collected and thematically coded for internalization, explanation, action, and exemplification. Of these 38 articles, 12 (31\%) incorporated internalization. For example, the MSF website discussed the negative impact of imposing a forced quarantine of asymptomatic health workers returning from West Africa to the United States. That is, there is no reason to quarantine asymptomatic people because asymptomatic people with the Ebola infection do not transmit the virus. The organization also emphasized the lack of risk the U.S. population faced when health care workers returned from fighting the epidemic in West Africa. In a press release following Dr. Craig Spencer's discharge from the hospital after contracting Ebola while working with MSF, for instance, the organization reiterated that asymptomatic people like Dr. Spencer cannot spread the virus and that "the public must not stigmatize and even threaten these volunteers" (Doctors Without Borders, 2014b).

A majority of the articles-36 (95\%) of 38-focused on explanation. For example, the MSF website posted this explanation about what was being done to contain the disease and treat infected patients:

MSF will work in collaboration with organizations, academics, companies, the Ministries of Health in the affected countries, and the WHO in order to implement fast-tracked clinical trials for some of the new treatments for Ebola at existing treatment sites. Experimental treatments are currently being selected and trial designs are being developed to 
ensure that disruption to patient care is minimal, that medical and research ethics are respected, and that sound scientific data is produced. (Doctors Without Borders, 2014b)

These kinds of explanations about what Ebola is, how it is contracted, and what is being done to contain it and treat patients were posted on each of the websites sponsored by the WHO, UNICEF, and MSF.

Of the 38 website articles, 25 (66\%) proposed specific action steps. An article posted on the WHO website (World Health Organization, 2014), for instance, explained that

WHO and its partners have recommended exit screening at airports and land-border crossings in countries affected by Ebola, and it is now an established practice. WHO stresses that only two categories of people should not travel: those who are infected and those identified as their close contacts as they may be infected with Ebola virus.

According to an article posted on the UNICEF website (Gilliam, 2014), "avoiding shaking hands is possibly the easiest of the [behavioral] changes" to make.

In terms of exemplification, $6(16 \%)$ of the 38 website postings used exemplars. More specifically, 4 (33\%) of the 12 articles that integrated internalization also used exemplars. For example, an MSF article described its "sickest patients" to be treated for Ebola and the "miracle" of their recovery. The MSF wrote, "When Hassan was brought in, he was almost dead. He wasn't moving or speaking; he had constant diarrhea; he was confused, disoriented, and lethargic" (Doctors Without Borders, 2014a). One of the 36 articles offering explanations did so using exemplars. This article was actually an infographic by UNICEF explaining what life-saving supplies had been delivered to Ebola-affected countries between August and November 2014 (United Nations Children's Fund [UNICEF], 2014). Finally, one exemplar was also identified as helping to convey self-protective action steps to be taken. UNICEF (2016) emphasized the important role of handwashing in preventing the spread of Ebola using the WASH acronym, which stands for "water, sanitation, and hygiene." 


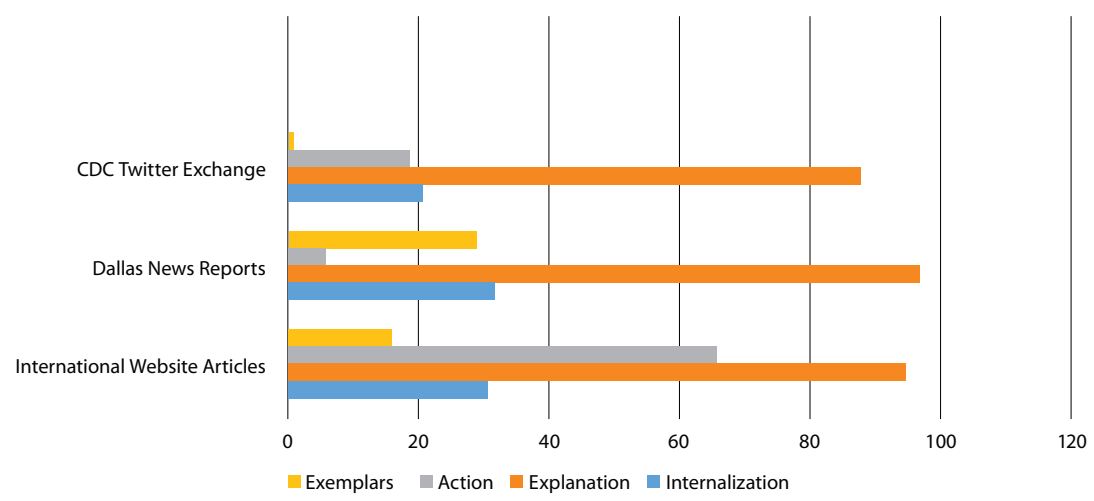

FIGURE 2 Comparative analysis of CDC Twitter exchange, Dallas area reports, and international organization websites.

In sum, a majority of international articles emphasized explanation over internalization or action, although more of these messages did offer action steps compared to the local newspaper reports or national CDC Twitter exchange. In addition, as was the case with the Twitter chat and Dallas area news stories, very few exemplars were offered, and of those that were, most were negative.

\section{Research Question 4}

Descriptive statistics from each of the distribution channels-local news stories and press releases; national CDC live Twitter chat; and international (WHO, UNICEF, MSF) website articles-were compared to discover similarities and differences regarding the use of IDEA model elements and exemplification in the Ebola crisis messages. Regarding the IDEA model elements, Figure 2 illustrates that $21 \%$ of the CDC Twitter feed, $32 \%$ of Dallas newspapers, and $31 \%$ of international organization newspaper reports incorporated internalization. The vast majority of messages across distribution channels focused primarily on explanation (88\% of the national CDC Twitter messages, $97 \%$ of the local Dallas news articles, and $95 \%$ of international organization website articles). With regard to the action element of the IDEA model, only $19 \%$ of the national CDC exchange tweets and $6 \%$ of the local Dallas area news reports offered specific actionable instructions. However, $66 \%$ of the international organization website articles proposed them. Finally, 
regarding exemplification, although exemplars can serve as cognitive shortcuts for translating complex subjects, fewer than $1 \%$ of the CDC Twitter messages, $29 \%$ of the Dallas news stories and press releases, and $16 \%$ of the international organization website articles used them. Moreover, those that did use exemplars tended to use negative rather than positive ones.

\section{Discussion}

This examination of messages distributed nationally via the CDC Twitter live chat, locally via Dallas area news stories and press releases, and internationally via website postings from the WHO, UNICEF, and MSF when the first case of and death from Ebola occurred in the United States yields some fruitful conclusions. Moreover, the conclusions give rise to some interesting implications and recommendations.

Perhaps the most formidable conclusion to be drawn from this analysis stems from the fact that messages shared by all sources via a variety of distribution channels focused extensively on explanation over internalization and action. Although multiple message-testing studies have confirmed that the most effective instructional risk and crisis messages integrate all three elements, this study reveals that current risk and crisis reporting practices continue to privilege explanation over internalization and action (e.g., D. D. Sellnow, Lane et al., 2015; D. D. Sellnow et al., in press; T. L. Sellnow, Sellnow, \& Helsel, 2017). This privileging of explanation is not surprising, however, in that it confirms the results of previous research, for example, by Frisby et al. (2014), who focused on news reports during the 2010 nationwide egg recall in the United States, and by D. D. Sellnow et al. (2016) regarding blended meat contamination in Sweden. However, if the goal of such instructional risk and crisis messages is learning, then it follows that they ought to contain elements that research has confirmed are necessary to achieve affective and behavioral, as well as cognitive, learning (e.g., Dewey, 1938; D. D. Sellnow \& Sellnow, 2014b). In fact, failing to do so could lead people to do nothing or to do precisely the wrong thing, which could result in devastating consequences (D. D. Sellnow et al., 2017). 
With regard to the Ebola outbreak megacrisis as experienced in the United States, failing to integrate internalization and action into most of the messages could have played a role in the level of fear felt by nonscientific publics seeking information about the crisis and how to protect themselves. To clarify, instructional risk messages that offer explanation without internalization often fail to achieve compliance, and even when specific action steps are offered, they are typically ignored or not sustained when internalization is not also integrated (D. D. Sellnow et al., 2017).

In the midst of a public health megacrisis like the 2014 Ebola epidemic, organizations ought to provide accurate information to diverse publics about what the disease is and how it is spread. All sources examined in this study (CDC Twitter exchange, Dallas area news stories and press releases, and international organization websites) did so. However, only the international organization website articles also offered specific self-protective action steps in a majority of them. It is certainly possible that, because the Ebola outbreak had been going on for some time in West Africa before it reached the United States, these organizations were more concerned with revealing actions needed to contain the spread of the virus than with providing general base-rate information about the virus. In other words, because the virus was spreading quickly in West Africa, emphasizing specific action steps may have been a more immediate concern. It is unfortunate that the CDC and Dallas new stories and press releases did not capitalize on sharing the abundance of information available from these international sources long before Ebola surfaced in the United States. Perhaps they considered it a "West African disease" and believed it would be contained there before having a chance to migrate overseas. Thus preparing U.S. publics to take preventative action may have appeared to be somewhat irrelevant prior to the Dallas case. This seems plausible, given that CDC experts reiterated many times that such an outbreak was highly unlikely in the United States owing to the access to advanced medical treatment centers. Regardless, previous research has suggested that messages including specific action steps tend to be most effective when preparing for a potential crisis as well as in response to crises (Frisby et al., 2014; T. L. Sellnow et al., 2017; D. D. Sellnow \& Sellnow, 2014b). 
With regard to exemplification, research has demonstrated that it can be a valuable cognitive shortcut for making complex information easier to process and retain (Spence et al., 2015). However, this analysis reveals that, overall, very few of the messages integrated exemplars. This is somewhat surprising, given that exemplars are commonly used in mass media generally (Aust \& Zillmann, 1996) and to achieve persuasive goals specifically (Brosius \& Bathelt, 1994). Moreover, negative exemplars were being shared throughout social media during this same time period. Not only that, but most of the exemplars that appeared in the Dallas area news stories were negative. The failure to offer positive exemplars in the messages shared by the CDC, Dallas news stories, and international organization websites as a counter to them appears to be an unfortunate oversight. Research has reported that positive exemplars can be effective in countering negative ones, reducing fear, and fostering self-efficacy, but only if they are actually offered and received by target populations (D. D. Sellnow \& Sellnow, 2014a; Spence et al., 2015; Spence, Sellnow-Richmond, Sellnow, \& Lachlan, 2016).

Findings from this study also suggest important recommendations both for crisis communicators and for future research. First, none of the three sets of messages examined offered a balanced integration of all three message content elements (internalization, explanation, and action) according to the IDEA model. Given conclusions drawn from existing research, failure to include all three may have contributed to a lack of motivation among receivers to attend to them as well as misunderstandings about the epidemic, its relevance, and what to do for self-protection. When communicating to nonscientific publics about risk and crisis epidemics, spokespersons reporting locally, nationally, and internationally may be wise to take strategic measures to incorporate each of these elements into their messages. Moreover, the various spokespersons ought to coordinate their efforts to ensure that message content and distribution efforts are consistent. To clarify, because people seek convergence among such messages during megacrisis events, doing so may help ensure that diverse publics (a) accurately understand what the disease is and how it is spread and (b) engage in appropriate actions for self-protection (Anthony \& Sellnow, 2011, 2016; T. L. Sellnow \& Seeger, 2013). 
Second, exemplification was rarely present in these instructional risk messages distributed locally, nationally, or internationally. When used strategically, exemplars can make complex information easier to understand and remember (Zillmann, 2006; Zillmann \& Brosius, 2000). They can also be used to counter misleading negative exemplars, which often go viral on social media (D. D. Sellnow \& Sellnow, 2014a; Spence et al., 2016). Incorporating positive exemplars may effectively reduce fear and heighten self-efficacy among disparate nonscientific publics receiving the messages. In the future, it may behoove crisis communicators to thoughtfully consider the strategic use of exemplification to bolster internalization by motivating receivers to attend, explanation by making complex information easier to comprehend and retain, and action by serving as a cognitive shortcut for instigating appropriate self-protective actions.

Finally, the results of this study point to the utility of doing additional research applying the IDEA model embellished with exemplification. Additional thematic and content analyses on existing crisis messages across distribution channels and crisis types could add to what we know about current practices. Surveys, interviews, and focus group studies could enhance our understanding of the effectiveness of instructional risk and crisis messages among various stakeholder groups. Similarly, additional message-testing experiments could inform our understanding of the effectiveness of such messages in achieving affective, cognitive, and behavioral learning outcomes among diverse people and groups in various countries and regions, regarding a variety of risk and crisis types, and distributed via a range of channels. Finally, although IDEA model messages have been tested empirically, confirming their utility in a variety of crisis situations, similar experiments ought to be conducted on messages designed specifically for Ebola to confirm the validity of potential recommendations offered to health organizations and media professionals charged with communicating about the disease. Such experiments could confirm the degree to which IDEA model messages instruct nonscientific publics specifically about Ebola (i.e., what it is, how it is spread, and what to do for self-protection) more effectively than status quo ones like those examined here. 


\section{Limitations}

We acknowledge several limitations of this study. First, we were able to collect more tweets than Dallas area news stories and press releases or website content provided by international health organizations. However, a more balanced sample of messages across sources and channels was not possible because more messages simply did not exist during the time frame of this case study. That said, we did examine a comprehensive census, which included everything available from those outlets during the time period. Moreover, if we take word count into consideration, the tweets were quite short and the news stories, press releases, and website articles considerably longer. Bearing this in mind indicates less imbalance among the sources than might be perceived by number alone. Second, the Ebola outbreak had been going on for many months in West Africa before it emerged in the United States. As such, the nature of the story lines was bound to be different in the local stories compared to the international articles, which may have complicated the results of the study. Finally, our decision to conduct a thematic analysis was based on the lack of work done across distribution channels (local, national, international) to date. Thus these exploratory results ought to be considered, as they may spur future research using different methodological approaches.

\section{Conclusion}

Indeed, effective risk and crisis communication when targeting nonscientific publics presents formidable challenges. When attempting not only to inform the public about an event but also to instruct them to take appropriate self-protective actions, the challenges become even more complicated. Moreover, when the event is a megacrisis that crosses international boundaries and impacts diverse publics, communicators must be strategic about the content to include in their messages and the channels through which they distribute them. The IDEA model for effective instructional risk and crisis communication embellished with exemplification may provide a workable framework for doing so. This Ebola epidemic analysis revealed, however, that current risk and crisis message practices continue to privilege explanation over internalization 
or action. Consistent messages coming from various health organizations and media outlets that integrate internalization, explanation, and action embellished with appropriate exemplars may achieve successful affective, cognitive, and behavioral learning outcomes among disparate nonscientific publics. As such, we may increase the likelihood that these messages will achieve what we intend from them-which is, of course, to save lives. 


\section{Appendix: IDEA Model Thematic Analysis Codebook}

\section{Internalization}

Goal: To get attention and to aid retention.

Question: Am I (or those I care about) affected, and how?

a. Compassion (People don't care how much you know, until they know how much you care.)

- Does the message say something to this effect (e.g., empathetic messages about supportive care being given to infected patients, as well as to their loved ones)?

b. Personal relevance

- How likely am I (or those I care about) to be affected?

- What and how severe might the consequences be?

c. Proximity

- Where is the event occurring, and how close is that to me and/ or those I care about?

- Is location specified, and to what specificity?

d. Timeliness

- When is the event occurring?

- How much time do I have to prepare?

- How much time do I have to respond if exposed?

- How much time do I have to respond if infected?

e. Exemplification

- What if any positive exemplars are offered to get attention and make it memorable?

- What if any negative exemplars are offered to get attention and make it memorable?

\section{Distribution}

Goal: To get the correct message to the target audience(s).

Question: What channel or channels is/are the message(s) being sent through?

- Convergence of multiple messages being sent through diverse channels. 


\section{Explanation}

Goal: Provide accurate information about what is happening and being done about the event.

Question: What is happening, and why?

a. Source credibility (international, national, local)

b. Accurate science, accurate information

c. What are the responsible agencies doing to deal with the event?

d. Intelligible translation for target audience?

e. Is exemplification used to help make complex information easier to understand, and if so, is it positive and helpful or negative in ways that foster misunderstanding?

\section{Action}

Goal: To empower people to take appropriate action to save lives.

Question: What should I (and those I care about) do (or not do) for self-protection?
a. Specific preparation action steps
b. Specific response steps
c. Exemplification in action steps? 
Deborah D. Sellnow-Richmond, $\mathrm{PhD}$, is assistant professor in the Department of Communication at Columbus State University, where she teaches courses in the public relations concentration. She researches the efficacy and unforeseen effects of public relations messages in health and organizational crisis contexts and the emerging role of social media in creating and resolving organizational crises.

Deanna Sellnow, $\mathrm{PhD}$, is professor of strategic communication and program coordinator of human communication in the Nicholson School of Communication at the University of Central Florida. She conducts research in two major areas. The first focuses on strategic instructional risk and crisis communication in a variety of contexts. The second focuses on rhetoric and persuasion in mediated popular culture texts.

Amiso M. George, $\mathrm{PhD}$, is associate professor, former director of the graduate program, and former chair of the Department of Strategic Communication at Texas Christian University. George worked as a journalist, broadcaster, and public relations consultant in Nigeria and the United States. Named a Carnegie African Diaspora Fellow for 2017, she is the author of several book chapters and journal articles on crisis communication. She consults in risk and crisis communication.

\section{ORCID}

Deborah D. Sellnow-Richmond (D) https://orcid.org/oooo-ooo1-6179 $-0307$

Deanna Sellnow (1) https://orcid.org/oooo-0oo3-4668-4359

\section{Note}

1. For the live Ebola \#CDCchat, see https://storify.com/CDCgov/live-ebola -cdcchat-october-2-2014\#publicize 


\section{References}

Anthony, K. E., \& Sellnow, T. L. (2011). Information acquisition, perception, preference, and convergence by Gulf Coast residents in the aftermath of the Hurricane Katrina crisis. Argumentation and Advocacy, 48, 81-96. https://doi.org/10.1080/00028533.2011.11821756

Anthony, K. E., \& Sellnow, T. L. (2016). The role of the message convergence framework in medical decision making. Journal of Health Communication, 21, 249-256. https://doi.org/10.1080/10810730.2015.1064497

Aust, C. F., \& Zillmann, D. (1996). Effects of victim exemplification in television news on viewer perception of social issues. Journalism and Mass Communication Quarterly, 73, 787-803. https://doi.org/10.1177/107769909607300403

Brosius, H. B., \& Bathelt, A. (1994). The utility of exemplars in persuasive communications. Communication Research, 21(1), 48-78. https://doi.org /10.1177/009365094021001004

Centers for Disease Control and Prevention. (2015, October 14). Preliminary study finds that Ebola virus fragments can persist in the semen of some survivors for at least nine months. Retrieved from https://www.cdc.gov/media /releases/2015/p1014-ebola-virus.html

Coombs, T. W. (2009). Conceptualizing crisis communication. In R. L. Heath \& H. D. O'Hair (Eds.), Handbook of risk and crisis communication (pp. 99-118). New York, NY: Routledge.

Dallas Independent School District. (2014, October 1). Frequently asked questions regarding Ebola. Retrieved from https://www.dallasisd.org/Page/31655

Dewey, J. (1938). Experience and education. New York, NY: Kappa Delta Pi. Doctors Without Borders. (2014a, October 20). Ebola: "Three Miracles" in Bo, Sierra Leone. Retrieved from http://www.doctorswithoutborders.org /article/ebola-three-miracles-bo-sierra-leone

Doctors Without Borders. (2014b, October 27). QઐA on MSF's Ebola response and protocols. Retrieved from http://www.doctorswithoutborders.org /article/q-msf\%E2\%80\%99s-ebola-response-and-protocols

Eagly, A. E., \& Chaiken, S. (1993). Process theories of attitude formation and change: The elaboration likelihood and heuristic-systematic models. In The psychology of attitudes (pp. 305-349). Fort Worth, TX: Harcourt Brace Jovanovich. 
Frisby, B. N., Sellnow, D. D., Lane, D. R., Veil, S. R., \& Sellnow, T. L. (2013). Instruction in crisis situations: Targeting learning preferences and selfefficacy. Risk Management, 15, 250-271. https://doi.org/10.1057/rm.2013.7

Frisby, B. N., Veil, S. R., \& Sellnow, T. L. (2014). Instructional messages during health-related crises: Essential content for self-protection. Health Communication, 4, 347-354. https://doi.org/10.1080/10410236.2012 .755604

Gilliam, E. (2014, October 8). In Cote d'lvoire, Ebola knocking on the door. Retrieved from https://www.unicef.org/infobycountry/cotedivoire_76203 .html

Governor's Press Office. (2014). Gov. Perry announces North Texas Ebola treatment and infectious disease bio containment facility [News release]. Retrieved from http://blog.methodisthealthsystem.org/wp-content/uploads/2014 /10/Gov-Perry-Announces-North-Texas-Ebola-Treatment-and-Infectious -Disease.pdf

Helsloot, I., Boin, A., Jacobs, B., \& Comfort, L. (2012). The new challenges of mega-crises. In I. Helsloot, A. Boin, B. Jacobs, \& L. Comfort (Eds.), Mega-crises: Understanding the prospects, nature, characteristics and the effects of cataclysmic events (pp. 5-11). Springfield, IL: Charles C. Thomas.

Kolb, D. A. (1984). Experiential learning: Experience as the source of learning and development. New York, NY: Prentice Hall.

Lindlof, T. R., \& Taylor, B. C. (2011). Qualitative communication research methods (3rd ed.). Thousand Oaks, CA: Sage.

Littlefield, R. S., Beuchamp, K., Lane, D. R., Sellnow, D. D., Sellnow, T. L., Venette, S., \& Wilson, B. (2014). Instructional crisis communication: Connecting ethnicity and sex in the assessment of receiver-oriented message effectiveness. Journal of Management and Strategy, 5, 16-23. https://doi .org/10.5430/jms.v5n3p16

Lupkin, S. (2014, October 18). Ebola scare turns Dallas hospital into a "Ghost Town." ABC News. Retrieved from http://abcnews.go.com/Health/ebola -scare-turns-dallas-hospital-ghost- town/story?id=26276610

Rosenstiel, T., Mitchell, A., Purcell, K., \& Rainie, L. (2011, September 26). How people learn about their local community. Retrieved from http://www .pewinternet.org/2011/09/26/part-5-the-role-of-the-internet/

Rowan, K. E., Botan, C. H., Kreps, G. L., Samoilenko, S., \& Farnsworth, K. (2009). Risk communication education for local emergency manag- 
ers: Using the CAUSE model for research, education, and outreach. In R. Heath \& H. D. O'Hair (Eds.), Handbook of crisis and risk communication (pp. 168-191). New York, NY: Taylor and Francis.

Seeger, M. W. (2006). Best practices in crisis communication: An expert panel process. Journal of Applied Communication Research, 34, 232-244. https:// doi.org/10.1080/00909880600769944

Sellnow, D. D., Iverson, J., \& Sellnow, T. L. (2017). The evolution of the operational earthquake forecasting community of practice: The L'Aquila communication crisis as a triggering event for organizational renewal. Journal of Applied Communication Research. https://doi.org/10.1080/00909882 .2017 .1288295

Sellnow, D. D., Johansson, B., Sellnow, T. L., \& Vigso, O. (2016, November). Communicating across continental divides: An empirical examination of the utility of the IDEA model for navigating (late) modernity's "new normal" in global crisis communication. Paper presented at the European Communication Research Education Association, Prague, Czech Republic.

Sellnow, D. D., Lane, D. R., Littlefield, R. S., Sellnow, T. L., Wilson, B., Beauchamp, K., \& Venette, S. (2015). A receiver-based approach to effective instructional crisis communication. Journal of Contingencies and Crisis Management, 23, 149-158. https://doi.org/10.1111/1468-5973.12066

Sellnow, D. D., Lane, D. R., Sellnow, T. L., \& Littlefield, R. S. (2017). The IDEA model as a best practice for effective instructional risk and crisis communication. Communication Studies, 68, 552-567. https://doi.org/10.1080/1051 0974.2017.1375535

Sellnow, D. D., Limperos, A., Frisby, B. N., Sellnow, T. L., Spence, P. R., \& Downs, E. (2015). Expanding the scope of instructional communication research: Looking beyond classroom contexts. Communication Studies, 66, 417-432. https://doi.org/10.1080/10510974.2015.1057750

Sellnow, D. D., \& Sellnow, T. L. (2014a). The challenge of exemplification in risk and crisis communication. Journal of Applied Communications, 98, 53-64. https://doi.org/10.4148/1051-0834.1077

Sellnow, D. D., \& Sellnow, T. L. (2014b). Risk communication: Instructional principles. In T. Thompson (Ed.), Encyclopedia of health communication (Vol. 17, pp. 1181-1184). Thousand Oaks, CA: Sage. https://doi .org/10.4135/9781483346427.n463

Sellnow, D. D., \& Sellnow, T. L. (in press). The IDEA model of effective risk 
and crisis communication by emergency managers and other key spokespersons. Journal of Emergency Management.

Sellnow, T. L., \& Seeger, M. W. (2013). Theorizing crisis communication. Malden, MA: Wiley Blackwell.

Sellnow, T. L., Sellnow, D. D., \& Helsel, E. M. (2017, March). Crisis communication in response to rapidly emerging diseases in the agriculture industry: Porcine epidemic diarrhea virus as a case study. Paper presented at the annual conference of the Central States Communication Association, Minneapolis, MN.

Sellnow, T. L., Sellnow, D. D., Lane, D. R., \& Littlefield, R. S. (2012). The value of instructional communication in crisis situations: Restoring order to chaos. Risk Analysis, 32, 633-643. https://doi.org/10.1111/j.1539-6924.2011.01634.x Southern Methodist University. (2014). SMU closely monitoring information about Ebola case in Dallas [News release]. Retrieved from http://www .smu.edu/News/2014/ebola-update-030ct2014

Spence, P., Lachlan, K., Lin, X., Sellnow-Richmond, D. D., \& Sellnow, T. L. (2015). The problem with remaining silent: Exemplification effects and public image. Communication Studies, 66, 341-357. https://doi.org/10.108o /10510974.2015.1018445

Spence, P. R., Sellnow-Richmond, D. D., Sellnow, T. L., \& Lachlan, K. A. (2016). Social media and corporate reputation during crises: The viability of video-sharing websites for providing counter-messages to traditional broadcast news. Journal of Applied Communication Research, 44, 199-215. https://doi.org/10.1080/00909882.2016.1192289

Texas Wesleyan University. (2014). Health center shares CDC's Ebola info, safety guidelines for college campuses [News release]. Retrieved from https:// txwes.edu/student-life/health/department-news/health-center-shares-cdcs -ebola-info-safety-guidelines-for-college-campuses/

United Nations Children's Fund. (2014). Life-saving supplies to Ebola-affected countries. Retrieved from https://www.unicef.org/supply/files/Ebola_sup plies_infographic_V2.pdf

United Nations Children's Fund. (2016, April 1). Water, sanitation and hygiene. Retrieved from https://www.unicef.org/wash/index_43107.html

World Health Organization. (2014, October). Guinea: screening for Ebola at Conakry International Airport. Retrieved from http://www.who.int /features/2014/airport-exit-screening/en/ 
World Health Organization. (2015, January). Origins of the 2014 Ebola epidemic. Retrieved from http://www.who.int/csr/disease/ebola/one-year-report /virus-origin/en/

Young, K. (2014, October 1). North Texas patient tested for Ebola virus. Retrieved from http://www.nbcdfw.com/news/health/North-Texas-Patient-Tested -for-Possible-Ebola-277529961.html

Zillmann, D. (1999). Exemplification theory: Judging the whole by some of its parts. Media Psychology, 1, 69-94. https://doi.org/10.1207/s1532785x mepo101_5

Zillmann, D. (2002). Exemplification theory of media influence. In J. Bryant \& D. Zillmann (Eds.), Media effects: Advances in theory and research (2nd ed., pp. 213-245). Mahwah, NJ: Lawrence Erlbaum.

Zillmann, D. (2006). Exemplification effects in the promotion of safety and health. Journal of Communication, 56, S221-S237. https://doi.org/10.1111 /j.1460-2466.2006.00291.x

Zillmann, D., \& Brosius, H. B. (2000). Exemplification in communication: The influence of case reports on the perception of issues. Mahwah, NJ: Lawrence Erlbaum. 